\title{
KEUSAHAWANAN WARISAN: SATU PEMERHATIAN DI KEMBOJA
}

\author{
RAJA ISKANDAR RAJA HALID*
}

\begin{abstract}
Abstrak
Selain daripada memberi gambaran tentang kehidupan lampau sesebuah tamadun, peninggalan warisan samada yang ketara atau tidak ketara kini mampu menjana pendapatan lumayan kepada sesebuah negara. Kemboja merupakan salah sebuah negara di Asia Tenggara yang kian pesat membangun hasil daripada industri pelancongan yang menampakkan daya keusahawanan warisan yang begitu dinamik. Perancangan, daya kreativiti dan pelaburan luar telah membantu Kemboja bangun dari kemelut peperangan yang mencengkam negara ini sejak beberapa dekad lalu. Tulisan ini adalah hasil pemerhatian awal tentang keusahawanan warisan di dua buah bandar di Kemboja, iaitu Siem Riep dan Phnom Penh yang telah merubah lanskap sosial dan ekonomi negara ini.
\end{abstract}

Kata kunci: Keusahawanan Warisan, kreatif ekonomi

\begin{abstract}
Apart from highlighting the past life of a civilization, both the tangible and intangible legacies are now able to generate good income to a country. Cambodia is one of the countries in Southeast Asia's that has been growing rapidly in terms of the tourism industry. This indicates a dynamic development of the entrepreneurial heritage. Planning, creativity and foreign investment have helped Cambodia raised from the crisis that has been gripping the country over the decades. This writing is the result of preliminary observations about the entrepreneurial heritage of two towns in Cambodia, Siem Riep and Phnom Penh that has changed the social and economic landscapes of the country.
\end{abstract}

Keywords: Entrepreneurship Heritage, creative economy

*Pensyarah Seni Persembahan di Fakulti Teknologi Kreatif dan Warisan, Universiti Malaysia Kelantan. 


\subsection{Pengenalan}

Kemboja adalah sebuah negara yang terletak di utara semenanjung Malaysia dan diapit oleh negara Thai di sebelah Barat dan Vietnam di bahagian Timur. Ia dikenali juga dengan nama Kingdom of Cambodia dan Kampuchea. Negara ini kian sembuh daripada beberapa siri pergolakan yang telah mengorbankan jutaan nyawa rakyatnya (Kiernen, 2008). Ia kini bangun semula daripada trauma yang telah menghantui negara tersebut sejak beberapa abad kebelakangan ini. Rakyat Kemboja sedang menempuh satu era baru di dalam evolusi negara mereka yang pernah dijajah oleh Perancis satu ketika dulu. Mereka kini mengeksploitasi segala hasil peninggalan warisan tamadun Khmer yang berkurun lamanya dan dijana oleh daya kreativiti generasi baru demi kesejahteraan masa depan negara mereka. Transformasi ini telah menimbulkan minat pihak Jabatan Warisan, Fakulti Teknologi Kreatif dan Warisan, Universiti Malaysia Kelantan untuk meninjau dengan lebih dekat keusahawanan warisan Kemboja untuk dijadikan model kepada pembangunan negeri Kelantan. Justeru itu pada bulan Julai 2011 satu rombongan telah dihantar untuk melawat negara Kemboja yang mempunyai banyak persamaan dengan negeri Kelantan dari sudut seni dan budaya.

\subsection{Sejarah}

Kemboja mempunyai sejarah kuno yang gemilang. Dari kurun ke-9 hingga ke-13 ia merupakan sebuah empayar yang kuat serta mempunyai tahap ketamadunan yang tinggi. Empayar Khmer ini mula

merosot pada abad ke-15 apabila ia diserang oleh Siam dan Vietnam. Kemboja terus menjadi rebutan kedua-dua jirannya ini yang akhirnya memaksa Raja Norodom (yang dilantik oleh Siam) untuk meminta pertolongan Perancis. Pada tahun 1867 Perancis telah menjadi protectorate dan ini berlarutan sehingga tahun 1953 apabila Kemboja mengisytihar kemerdekaan. Sebelum itu Jepun telah menakluki Kemboja dari tahun 1941 sehingga 1945.

Pada tahun 1970 Putera Norodom Sihanouk telah digulingkan oleh General Lon Nol dalam satu rampasan kuasa. Kemboja dikuasai oleh rejim Khmer Rouge di bawah pimpinan Pol Pot dari tahun 1975 sehingga 1979. Ini merupakan satu titik hitam di dalam sejarah negara ini apabila jutaan rakyatnya telah dibunuh di dalam proses "pembersihan" yang dilakukan Pol Pot. Rejim ini akhirnya dikalahkan oleh Vietnam dan berundur ke kawasan pedalaman. Tahun 1980-an menyaksikan berlaku perang saudara di antara beberapa puak yang bertelagah. Kemboja akhirnya mencapai keamanan pada tahun 1991 dan dua tahun kemudian Putera Norodom Sihanouk kembali ke negara ini dan ditabal semula sebagai Raja. Anakanda beliau Norodom Sihamuni mengambil alih sebagai Raja Kemboja pada tahun 2004.

\subsection{Keusahawanan Warisan dan Pelancongan}

Keusahawanan atau entrepreneurship adalah satu gerakan ekonomi yang sangat besar dan berpengaruh selama dua abad kebelakangan ini. Ia bukan sekadar perniagaan tetapi merangkumi penjanaan idea bernas yang direalisasikan dengan mengambil risiko tertentu. Kuratko (2009: xviii) berpendapat bahawa: 
The process of transforming creative ideas into commercially viable businesses continues to be a major force in today's world economy. Successful entrepreneurship requires more than merely luck and money. It is a cohesive process of creativity, risk taking, and planning.

Warisan meliputi keseluruhan peninggalan tradisi yang kita hargai sebagai sebuah masyarakat, yang diwarisi sejak turun temurun dan ingin diturunkan kepada generasi yang akan datang. Ia termasuk bahan-bahan fizikal, seperti artifak dan bangunan (tangible) serta budaya dan cara hidup (intangible). Kemboja kini mengeksploitasi sepenuhnya kedua-dua jenis warisan ini. Dengan perancangan rapi dan kreativiti negara ini berjaya menyajikan satu destinasi pelancongan yang amat menarik kepada dunia.

Di dalam usaha meningkatkan industri pelancongan, kerajaan Kemboja telah membuat perancangan teratur untuk membaikpulih dan memperkenalkan tapak-tapak warisan yang telah diiktiraf oleh UNESCO kepada dunia. Justeru itu sebuah badan Authority for the Protection and Management of Angkor and the Region of Siem Riep atau singkatannya APSARA telah ditubuhkan pada tahun 1995 untuk mengurus serta mengawalselia tapak-tapak bersejarah di Angkor dan sekitar Siem Riep dengan bantuan beberapa buah negara. Pada tahun 1992 Chantiers-Écoles de Formation Professionnelle (CEFP) telah ditubuhkan untuk melatih remaja berusia di antara 18 dan 25 tahun di dalam bidang kraftangan seperti ukiran batu dan kayu serta lukisan sutera. Akhirnya pada tahun 2001 Artisans d'Angkor ditubuhkan dengan bantuan kewangan dari Kesatuan Eropah di bawah program REPLIC (Programme Rural d'Éducation Professionnelle et Logique d'Insertion au Cambodge). Kini Artisans d'Angkor telah didaftarkan sebagai sebuah syarikat yang mempunyai lebih 1,000 orang pekerja.

Usaha ini membuahkan hasil dan kini industri pelancongan merupakan penyumbang kedua terbesar kepada ekonomi Kemboja selepas industri tekstil. Kehadiran pelancong meningkat dari tahun ke tahun dan pada tahun 2007 industri ini bernilai USD1.4 bilion. Enam bulan pertama tahun 2011 telah menyaksikan kedatangan 1.3 juta pelancong dan dijangkakan akan mencecah 2.73 juta untuk keseluruhan tahun ini (www.investcambodia.com). Pelaburan sektor pelancongan juga bertambah di Kemboja. Sehingga penghujung bulan Mei 2011, pelaburan berjumlah USD2.616 bilion yang melibatkan 42 projek pelancongan besar-besaran telah diluluskan oleh kerajaan Kemboja (www.cambodiatraveltours.net).

\subsection{Warisan Ketara}

Warisan ketara termasuk bangunan dan tempat-tempat bersejarah, tugu, artifak dan sebagainya, yang dianggap penting untuk dipelihara. Ia juga merangkumi objek-objek yang dianggap penting dari sudut arkeologi, senibina dan teknologi sesuatu budaya tertentu. Kemboja kini masyhur di serata dunia dengan tapak-tapak arkeologi yang mendapat pengiktirafan UNESCO sebagai tapak warisan dunia. Di antara tempat-tempat arkeologi yang terkenal di Angkor, Siem Riep termasuk Angkor Wat, Angkor Thom, Bantaey Srei, Bayon dan Ta Prohm yang telah diperkenalkan melalui filem Hollywood (TOMB RAIDER) pada tahun 2001. Kemboja juga mempunyai warisan semulajadi iaitu tasik air tawar yang terbesar di Asia Tenggara iaitu Tonle Sap yang didiami oleh masyarakat Vietnam dan Cham. 


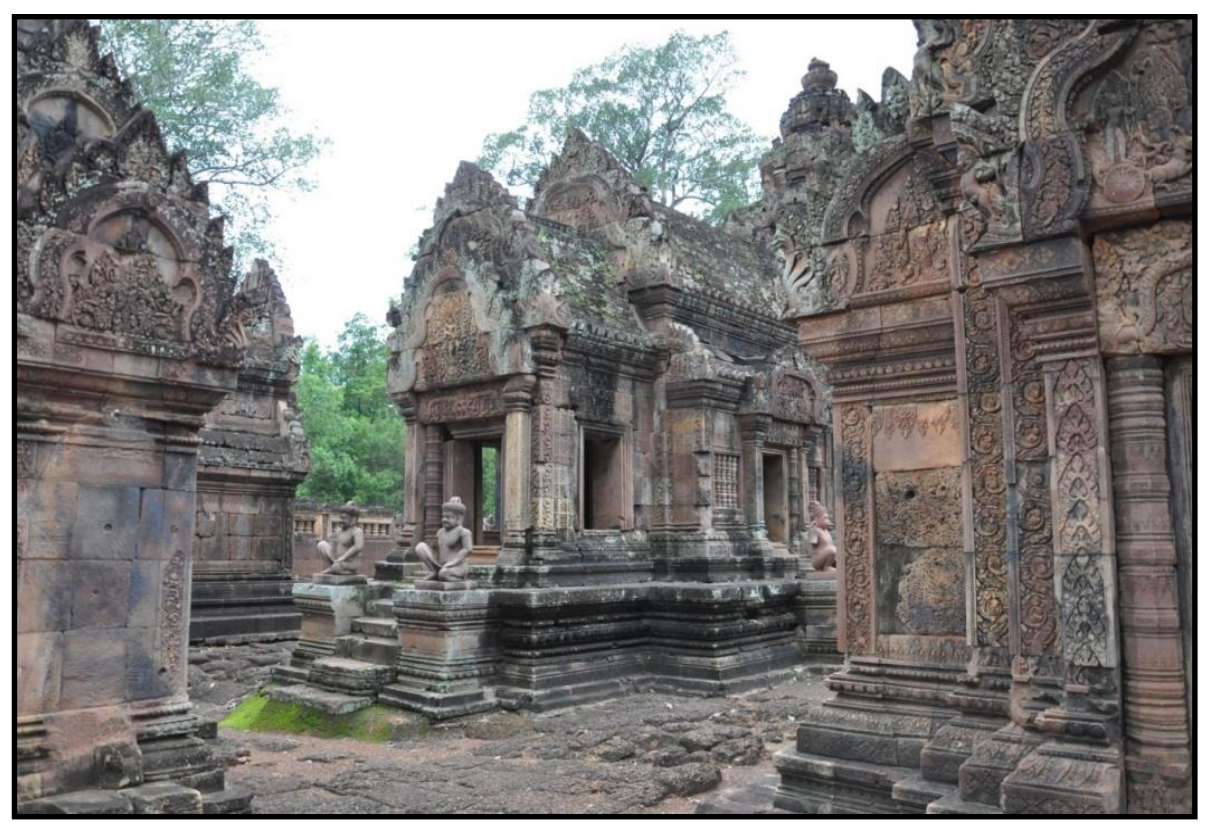

Foto 1 : Kuil Hindu Kurun Ke-10 di Banteay Srei, Angkor

(Gambar: Raja Iskandar Bin Raja Halid)

\subsection{Warisan Tidak Ketara}

Menurut Konvensyen Pemuliharaan Warisan Tidak Ketara UNESCO 2003, warisan budaya tidak ketara atau intangible cultural heritage ( $\mathrm{ICH})$ merupakan tunjang kepada kepelbagaian sesebuah budaya dan pemuliharaannya dapat memastikan kesinambungan daya kreatifnya. Konvensyen tersebut juga menyatakan bahawa ICH merangkumi:

- Tradisi Lisan dan ekspresi termasuk bahasa sebagai pemangkin kepada ICH.

- Seni Persembahan (seperti muzik tradisional, tarian dan teater).

- Amalan sosial (adat), ritual dan acara keraian.

- Pengetahuan dan amalan berkaitan alam dan cakerawala.

- Kraftangan tradisional (www.unesco.org).

\subsection{Seni Persembahan}

Salah satu tarikan pelancong yang berkunjung ke Kemboja ialah seni persembahan. Tarian klasik Apsara yang pada suatu ketika dulu telah pupus dan dihidupkan semula pada kurun ke-18 dan ke-20. Usaha ini telah diterajui oleh Raja Ang Duong yang memerintah dari tahun 1841 hingga 1869 dan berpandukan kesenian serta tema traditional Khmer. Kebanyakan daripada tarian-tarian tradisional ini telah diperhalusi dan diperkembangkan di antara tahun 1940-an dan 60-an di bawah seliaan serta naungan Permaisuri Sisowath Kossamak (ibu kepada Putera Norodom Sihanouk) di Conservatory of Performing Arts dan the Royal University of Fine Arts di Phnom Penh. Tarian ini hampir pupus semasa pemerintahan Rejim Pol Pot pada pernghujung tahun 70-an dan berjaya dipulihkan semula pada tahun 1980-an oleh Puteri Bopha Devi. Tarian Apsara kini dipersembahkan di tujuh buah restoran dan hotel sekitar Siem Riep dan satu di Phnom Penh (www.canbypublications.com). 
Muzik tradisional Khmer juga masih dipertahankan oleh masyarakatnya. Kumpulankumpulan muzik vung phleng pin peat jelas kelihatan di tempat-tempat pelancongan dan mengiringi tarian apsara. Pemuzik-pemuzik solo yang bermain alat roneat ek juga kelihatan di restoran-restoran sekitar Siem Riep. Alat-alat muzik seperti tror khse bey sejenis alat gesekan bertali 3 seakan rebab dan skor arakk alat pergendangan seperti gedombak dijual di merata-rata tempat dengan harga serendah USD10.

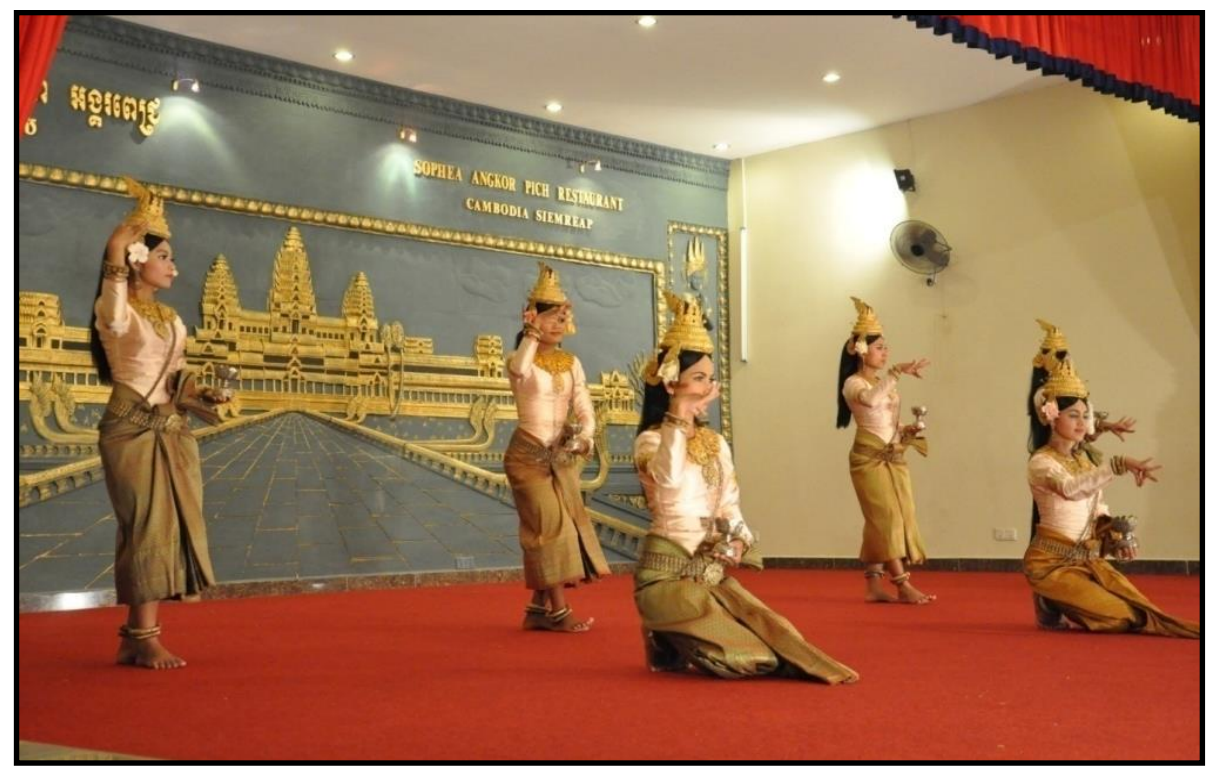

Foto 2: Tarian traditional Apsara Yang Dipersembahkan di Sebuah Restoran di Siem Riep (Gambar: Raja Iskandar Bin Raja Halid)

\subsection{Persembahan "Smile of Angkor"}

Pengunjung ke Siem Riep kini boleh menyaksikan sebuah persembahan teater muzikal yang memaparkan kombinasi elemen tradisional dan teknologi moden. Teater ini bertajuk "Smile of Angkor" dan telah menelan belanja USD5 juta untuk dihasilkan. Ia mula dipersembahkan pada bulan November 2010 dan kini telah menjadi tarikan tetap kepada pelancong yang mengunjungi Siem Riep. Produksi 75 minit ini adalah gabungan daya kreativiti Kemboja dan China yang menggunakan 104 orang artis yang 90 peratus daripadanya adalah rakyat tempatan. Mereka ini adalah di kalangan anak yatim serta golongan miskin yang dilatih sebagai penari dan penyanyi.

Dipromosikan sebagai "number one epic performance in Southeast Asia", produksi ini menceritakan sejarah Empayar Khmer dan merupakan cerminan budaya Khmer kepada dunia. Purata penonton sehari adalah seramai 300 orang di dalam dewan yang mampu mengisi 800 orang dan tiket untuk setiap orang adalah di antara USD33-48, termasuk makan malam dan pengangkutan. Dari sudut teknologi kreatif dan warisan, dan ditambah nilai keusahawanan, persembahan "Smile of Angkor" ini merupakan satu contoh kecemerlangan. 


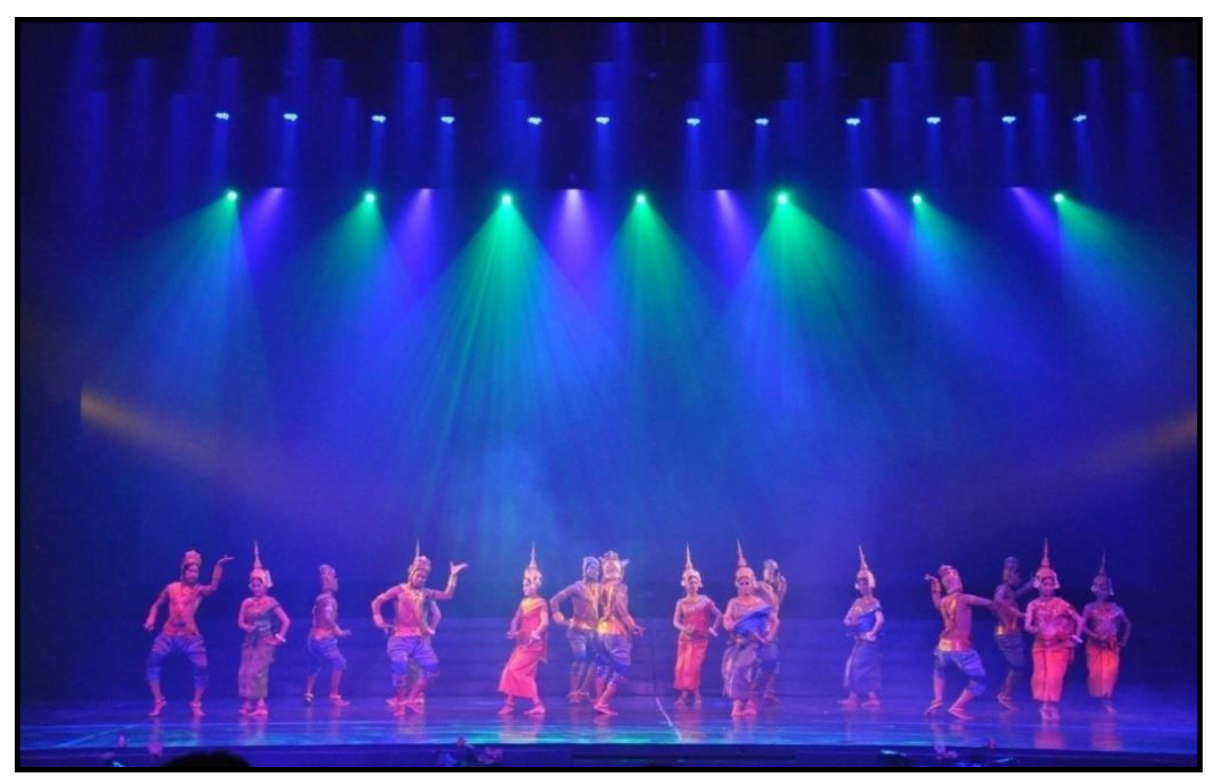

Foto 3: Persembahan "The Smile of Angkor" di Siem Riep

(Gambar: Raja Iskandar Bin Raja Halid)

\subsection{Rumusan}

Keusahawanan bukan sekadar perniagaan tetapi usaha yang memerlukan daya kreativiti dan inovasi yang tinggi serta keberanian mengambil risiko. Warisan ketara dan tidak ketara telah dijadikan tarikan pelancong sekaligus meningkatkan pendapatan sesebuah negara. Walaupun masih mundur dari banyak aspek, Kemboja mampu memelihara warisannya melalui penubuhan badan-badan yang mengawal serta melatih pelapis di dalam bidang kesenian dan budaya dengan sokongan pihak istana. Dengan bantuan beberapa negara, Kemboja telah berjaya membangunkan ekonominya melalui industri pelancongan dengan mengekploitasi warisan ketara dan tidak ketaranya. Negara ini juga mampu mencetus daya kreatif dan keusahawanan dengan menghasilkan kraftangan serta cenderahati berunsurkan elemen-elemen warisan ketaranya. Dari kemeja-T dan beg kulit, sehinggalah ukiran batu dan lukisan, barangan ini juga dijual dengan harga yang berpatutan. Salah sebuah syarikatnya juga mampu mengambil risiko yang besar di dalam mementaskan produksi teater yang berjaya menjana pendapatan lumayan. Tidak hairanlah Kemboja kini menjadi salah sebuah negara yang paling pesat membangun di dunia.

Sebagai sebuah negeri yang berpotensi sebagai penarik pelancong, Kelantan perlu mula mengambil langkah memelihara serta membangunkan seni budaya dan warisan ketara serta tidak ketara. Ini termasuk mengenalpasti tapak-tapak bersejarah untuk dibaikpulih dan dibangunkan. Pengusaha industri kreatif juga boleh mengenalpasti motif, corak, warna, rekabentuk, gerak, bunyi yang boleh diidentifikasikan sebagai representasi budaya setempat. Perlu dilakukan usaha penjenamaan semula atau rebranding tempat-tempat yang berpotensi dari segi rekabentuk grafik, signage, senibina, warna dan perancangan bandar. Usaha juga perlu dipertingkatkan lagi dari segi produksi barangan cenderahati (souvenirs) yang pelbagai dan mempunyai global appeal. Ini dilengkapkan dengan menyediakan persekitaran yang kondusif, bersih dan selamat kepada pengunjung. 


\section{Rujukan}

Albanese, M. (2006). Angkor: Splendors of the Khmer Civilization. Bangkok: Asia Books.

Kiernen, B. (2008). The Pol Pot Regime: Race, Power and Genocide in Cambodia under the Khmer Rouge, 1975-79. Yale: Yale University.

Kuratko, D.F. (2009). Entrepreneurship: Theory, Process, and Practice. Mason: South-Western Cengage Learning.

Miller, T.E. \& Williams, S. (Eds.). (2008). The Garland Handbook on Southeast Asian Music. New York: Routledge.

www.unesco.org

www. canbypublications.com 